\title{
The Construction of Organizational Structure : Connections with Autopoietic Systems Theory
}

\author{
Kumudinei Dissanayake \\ Meiji University \\ E-Mail: k_dis@hotmail.com \\ Masayasu Takahashi \\ Meiji University \\ E-Mail: taka-masa@ttv.ne.jp
}

\begin{abstract}
This study aimed to conceptualize the formation of organizational structures from the constructionist perspective. Avoiding the extremisms in equilibrium- and processbased theories, it adopts a recursivity-based approach, and draws most of its theoretical foundation from autopoietic systems theory. This study finds that organizations possess a "system organization," formed through the shared sense of their actors and a "structural configuration," which is founded on this shared sense. Based on the shared sense, this structural configuration is shaped by both formal organizational architecture and the temporal and contextual interactive processes of organizational actors. It suggests that organizational structures are unique constructions, subject to temporal and contextual variation.
\end{abstract}

Keywords: Constructionist Perspective, Organizational Construction, Organizational Structure, Autopoietic Systems Theory, Structural Configurations

\section{INTRODUCTION}

The view that organizations are subjective constructions, sensed through objective frameworks, has attracted a lot of research interest in current organization theory. Recent researches have used the constructionist perspective to study (micro) interactive processes within organizations. However, the structural configuration of organizations from the (organizational) constructionist perspective has yet to be researched. This study 
aimed to fill this knowledge gap by conceptualizing the formation of organizational structures from the organizational constructionist perspective. Examining organizational structures that constitute the "building blocks" of organizations, and theorizing of their formation, offers approaches for the purposeful construction of more flexible, smoothly functioning organizations.

Initially, organizational structures were studied in the functionalist organization theories (equilibrium-based theories), and subsequently in the interpretationalist organization theories (process-based theories). Moreover, organizational structures have been conceptualized in social systems theory. Avoiding the extremism inherent in equilibrium theories and process theories, this study based its theoretical foundations on recursivity-based theories. Following the introduction, the study briefly reviews three major approaches for studying organizational structures. Then, it highlights the distinguishable characteristics of the autopoietic systems theory. Beginning with a brief discussion of the main concepts of the organizational constructionist perspective, and following with an investigation of the implications of conceptualizing organizational structures using this approach, it next identifies the formation of structural configurations in organizations. The study concludes with an outline of the theoretical and practical implications of the results.

\section{THREE APPROACHES FOR STUDYING ORGANIZATIONAL STRUCTURES}

Early views on organizational structure may be traced back to the functionalist organization theory, which addressed the need for order and integration in organizations. Following this tradition, early conceptions on organizational structure were based on the orderly and integrated patterns of work structures in organizations. These theories were better named as equilibrium theories. For instances, bureaucratic theory of Weber (Gerth and Mills, 1948) and administrative process theory (Fayol, 1949) were primary theorizations of organizational structures. The structural contingency theory (Donaldson, 2001) and configurational approach (Mintzberg, 1979) have been noted as later developments. However, equilibrium theories have been questioned in light of the reality of the unintended consequences of actions that make organizational processes nondeterministic and lead to disequilibrium. Thus, process theories assumed a more subjective orientation by focusing on the subjective actions of individuals (Hernes and Bakken, 2003). Accordingly, in structural studies, organizational functions being replaced by organizational actions (e.g., Silverman, 1970), organizational structures were studied as processes rather than systems of functions. The conceptions of organizing (Weick, 1979) and enactment (Weick, 1995) sharpened the process-based view of 
organizational configurations. However, both equilibrium-based theories and processbased theories are based on two extremist positions when it comes to theorizing organizational structures.

Conversely, recursivity-based theories offer a non-extremist standpoint in which both structural stability and instability have been taken to consideration. Recursivitybased theories, which accommodate a view that both the structure and the process interact and change through mutual interactions (e.g., Giddens, 1979), the ongoing interactions of organizational actors or subunits recurrently process resources and information (e.g., Dow, 1988), and those occupy self-productive, self-organized, and self-maintained structures (e.g., Luhmann, 1990; 1995) present a view that organizational structures are recursively organized (Hernes and Bakken, 2003).

Among these theorizations, the autopoietic systems theory, which analyzes systems as having a self-productive nature (e.g., as self-organized and self-maintained systems), seems to be more informative with respect to providing insights for this study. On these grounds, we next examine the characteristics of autopoietic systems, in order to provide a more comprehensive theorization of organizational structures within the domain of the organizational constructionist perspective.

\section{STRUCTURE IN AUTOPOIETIC SYSTEMS THEORY}

In an analysis of living systems, Maturana and Varela first introduced the autopoiesis theory into the field of biology, focusing on the self-generative nature of living systems. Luhmann (1995) set forth the view that not only living systems, but also psychic systems (people) and social systems (interactions and societies) are also autopoietic systems. According to Luhmann, psychic and social systems reproduce processes of meaning. Luhmann's theory is called "social autopoietic theory" (Johannessen, 1998).

\section{Distinguishable Characteristics of Autopoietic Systems}

Autopoietic systems theory is distinguishable from other systems theories by its distinctive character. In the main, the survival of autopoietic systems is bound to their process of self-creation. All elements, processes, boundaries and structures of autopoietic systems are (self-) produced by the system itself (Bausch, 2001). Self-production arises from the cyclical linkage of self-organizing processes of the system. More particularly, a system is said to be self-organized if its components are constituted in a way that they spontaneously assume a particular order. The system boundary and the supply of energy are required for the self-production of the system, and particularly, self-maintenance 
means preservation of the identity of the system (Tenbner, 1993). Further, autopoietic systems are viewed as self-referential systems that can continue to organize and reproduce as systems only with reference to themselves (Whitaker, 1995). The selfreferentiality of operations and processes within a system is a requirement for the system's unity and identity (Tenbner, 1993). Thus, self-referentiality is a requirement for system stabilization.

\section{Structure of Autopoietic Systems}

Autopoietic structures are constantly modified by their interactions (internal and external). It means that these structures assemble, disassemble, and reorder themselves constantly. Thus, the organization of the system stays constant and constrains the activities of its structure. Subsequently, the structure varies according to the organization. Moreover, the organization of an autopoietic system is an abstract generalization that determines the identity of the system. Therefore, the organization functions as the dynamic for interaction within the system, and within this context the components interact with each other (Stacey, 2001). On these grounds, the inherent nature of the autopoietic structure is that of constant self-renewal. Thus, the role of internal operations comprises the production of its elements, structures, processes, boundaries, as well as the unity of the system.

\section{Autopoietic Systems and the Environment}

An autopoietic system is characterized by an open structure and a closed organization in which the structure becomes a component of its organization (Bausch, 2001). The operational (or organizational) closure of autopoietic systems means that external forces do not determine the system organization, its identity, or its structure. Autopoietic systems exist in an environment from which they gather required energy, as well as the building blocks of their elements. Although the import of energy, materials, and information, and the export of waste are fundamental to its survival, the system's identity is determined by its own operations, thereby assuring the impossibility of direct influence from the external environment. They differentiate themselves and the environment so that they may create their identity and the boundary. In that sense, it assures the impossibility of receiving direct influences from the external environment. 


\section{STRUCTURAL CONFIGURATIONS FROM ORGANIZATIONAL CONSTRUCTIONIST PERSPECTIVE}

Organizational construction (Dissanayake, 2004 (a)), which borrows its main ideas from the social constructionist perspective, indicates in a simplified sense that organizations are constructions of their actors. More specifically, organizational construction refers to a process of shared sense-making, a process that emerges through actor interactions directed toward the achievement of commonly agreed-upon purposes. In this sense, the primary mechanisms of organizational construction are identified as (1) actor interaction, (2) shared sense-making, and (3) the construction of meaning in organizational settings. More importantly, it presents a view that organizational rationality, organizational effectiveness and efficiency, and the organizational environments are all time-bound and context-bound constructions.

This perspective recognizes "intentionality" as a major phenomenon useful for contrasting organizational construction in relation to social construction by highlighting the fact that organizations actually exist for the purpose of organizing. Therefore, organizations are, by nature, intentional and purposive in action, organized for the achievement of a shared, agreed-upon purpose, and controlled for the purpose of action. More particularly, the conscious and deliberate nature of organizational processes is signified in organizational construction.

Organizational construction may be viewed as a conscious and deliberate (objective) process, in which the constructive roles of managers become significant; conversely, the process may be seen as a random, unconscious (subjective) occurrence that arises through the interactions of organizational actors. Thus, the process of organizational construction has been understood partly as a conscious and deliberate process of organized action, and partly as a random and unconscious process of interaction.

The argument that organizations are objectively organized entities is validated by the distinctive nature of organizations. That is, as systems of concerted action that exist to achieve commonly agreed-upon purposes (which require a degree of control within the particular system); organizations demonstrate an inherently objective character for their actions. However, the fact that meanings in the work environment are constructed in actor-interaction processes implies that organizations inherently accrue a subjective dimension. Moreover, this subjective character suggests that organizations are contextbound and time-bound constructions and, similarly, that multiple organizational constructions may exist in different contexts at different times. 


\section{Implications for Structural Configurations}

Organizational construction, configured with its distinctive characteristics as briefly reviewed above, implies an organizational structure that has both objective and subjective existing together. Similarly, organizational construction, which theorizes that organizational rationality, organizational effectiveness and efficiency, and the organizational environment are each constructions of organizational actors, suggests that organizational structure is a construction. Moreover, organizational construction includes the recognition of formal structural dimensions in an objective sense, while allowing at the same time, a conceptualization of structure as configured through time-bound and context-bound constructions, resulting in organizational actor-interaction processes at the interaction level. The view that organizations are objectively organized and subjectively constructed leads to the understanding that organizational structure is objectively structured by means of organizational formalities, and that it is subjectively structured in time and context through the shared sense making process of organizational actors. In other words, organizational structure in a constructionist perspective allows for the conceptualization of a temporal and contextual construction that is based on a formally regulated normative structure.

Consequently, we see an implied separation of the "system organization" from the "structural configuration" of an organization. The system organization could be considered as the status quo of the organization, on which the organization's structure is configured. Thus, the system organization becomes the feed back provider for its structural formation. Therefore, we can infer that the system organization is comparatively stable as compared to the structural configurations. Simply put, this conception suggests the impossibility of direct influences and controls that are exerted from the external environments, in that the organizational environment, too, is a construction of organizational actors (Dissanayake, 2004 (b)).

\section{Organizational Structure from the Autopoietic Systems Viewpoint}

In line with the fundamental views of autopoietic systems theory, we examined the formation of organizational structure, as conceptualized from an organizational constructionist perspective. However, our adoption of autopoietic systems theory does not lead to the argument that organizations are autopoietic systems. Rather, we are utilizing this theory of the unobservable mechanisms of human organisms in order to analyze the unobservable actions of human organizations.

After having examined the theoretical reviews of organizational structure in organization theory, we are of the opinion that each organization is constructed based 
upon a "system organization". The foundation of this system organization includes the shared sense of organizational actors, which is a construction that emerged through their interactive processes. Through this, they develop a sense of rationality (within their sphere of work), an idea of the criterion of effectiveness and efficiency, and an awareness of the environment of their organization. This kind of shared sense is taken as an objective reality (Berger and Luckmann, 1967) by the organizational actors. This characterization of objective features offers a way of directing and exercising control over organizational structure. The shared sense of organization thus described lies in the idea that the organization is a construction that is not stable, and subject to change.

In this sense, organizational structure denotes the specific arrangement of organizational actions at a particular time and in a specific context. In accordance with the theoretical trends inherent in the organizational constructionist perspective, the idea of organizational structure may be identified with a primary and a secondary structure that is bound together. The primary structure of an organization may be defined as its formal relationships, functions, coordination systems as reflected by organization charts, coordinative mechanisms etc. (Pennings, 1992). Conversely, secondary structure may be considered to be the patterns of interactions at a particular time and context.

On these grounds, the present study suggests that structural configuration of any organization is based on the shared sense of its actors, and is shaped by both its existing formal organizational architectures and the interactive patterns of its actors. Figure 1 below diagrams this theoretical explanation.

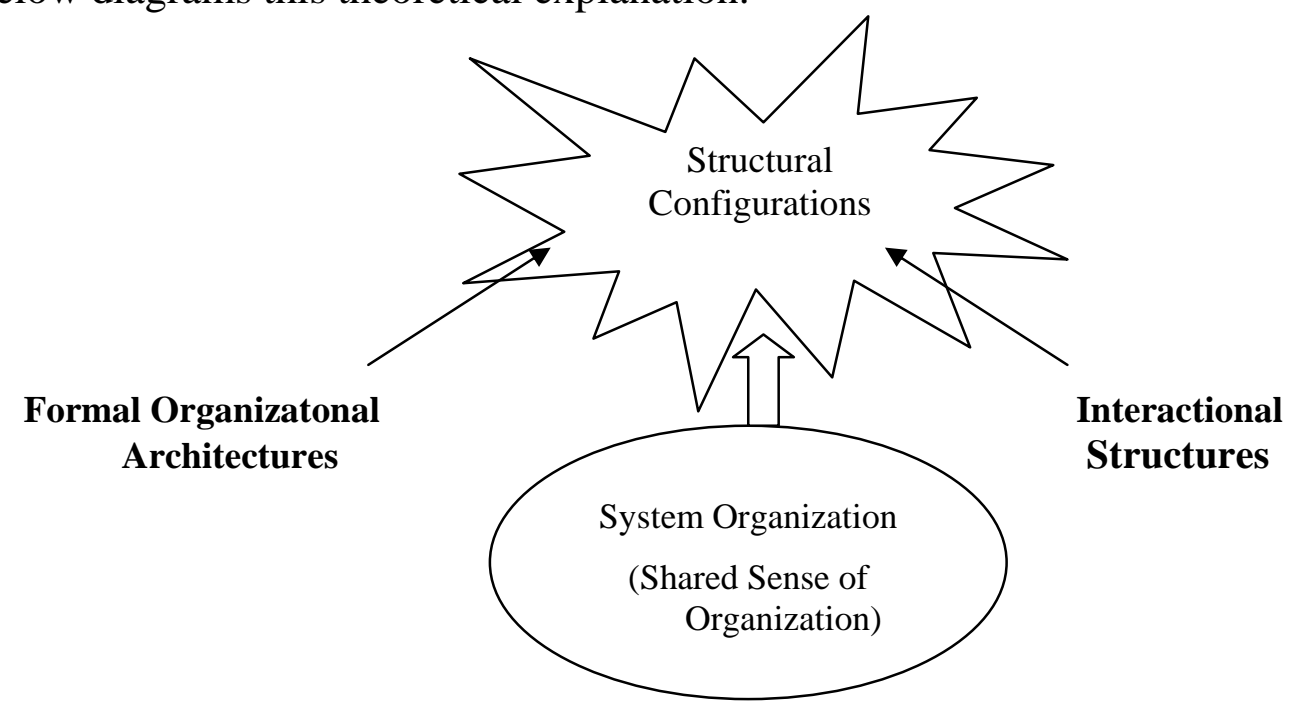

Figure 1 System Organization and Structural Configurations 
As shown in the above figure, the organizational structure is founded on the system organization from which it receives feed back for structural change. The structural configuration of the organization is unstable, and has room for short-term modification. The structural configuration may vary with time and context in relation to the patterns of interaction within a particular organizational context. However, this flexibility depends on the strength of the formal and interactional structures of the organization. For example, if the formal organizational architecture is relatively strong within a given time and context, accordingly, the structural configuration will be quasi-stable or unstable. Direct environmental influences on structural configurations in this theorization are not considered, as the environment is also a shared construction, and the structural configuration is founded on that shared construction.

This explanation will be proven in the real world organizations. For instance, any formal or informal, for-profit or not-for-profit, or virtual organization has a shared sense of organization as constructed through the interactions of its actors. At the same time, each organization possesses a formally prescribed pattern of behaviors. Each organization may experience patterns of interaction beyond the prescribed set of behaviors. Thus, it is possible to consider that the structural configuration of an organization at a particular time and context is a formation emerged through the combination of those three components (system organization, formal organizational architecture, and the interactive structure). Moreover, if any structure is seen to be rigid (or inflexible), it implies that the interactive processes among organizational actors are comparatively inactive, allowing prescribed formal architectures to be more activated in the particular context.

In summary, the system organization (or the shared sense of organization) can be viewed as the "mode of operation" that produces, shapes, and retains the identity of the system. The structural configuration at a particular time will display the abstraction of the net of relationships and interactions that form the unity of the system. Therefore, organizational structure is the specific arrangement of the organization at a particular time and in a particular context.

\section{CONCLUSIONS}

Our study attempts to understand the structural formation of organizations given the view that organizations are active constructions of their actors and bound to the time and context of their particular construction. Drawing from autopoietic systems theory, we recognize that organizations possess both a system organization formed through the shared sense of actors, and a structural configuration that is based on the shared sense. The structural configuration is a combined formation of the formal organizational 
architectures and the temporal and contextual interactive processes of organizational actors. Being coincide with the constructionist view of organizations, this theorization proves that organizational structures are normatively based, but at the same time, interactionally constructed time-bound and context-bound configurations. Thus, we propose that organizational structures are better imaged as unique constructions of organizational actors, subject to timely and contextual variations.

The theoretical value of this insight lies in its conceptual amalgamation of the normatively structured formal organizational blueprint and the interactionally structured temporal and contextual construction of organizational configurations. The empirical validity of this conceptualization is proven by its refection of real world organizations, which are bound to normative (internal and external) constructs and, at the same time respond to the timely and contextual requirements that are apprehended by organizational actors. Furthermore, this kind of thinking about structure applies to any type of organization-formal or informal, for-profit or not-for-profit, or virtual.

This kind of conceptualization does not consider organizations as isolated, but structurally coupled to other organizations in the environment. This structural coupling can be viewed as occurring in an isomorphic environment in which organizational fields are conceptualized (DiMaggio and Powell, 1991). Such a structural coupling is not an adaptation to its environment, but a part of the structural evolution itself. This conceptualization does not adopt the structural contingency of organizations (Donaldson, 2001), but it suggests the possibility of existing time-bound and context-bound unique configurations of organizations in which it partly accommodates configurational thinking (Mintzberg, 1979), and avoids its criticism over too few configurations (Donaldson, 2001, Takahashi, 2000).

The present study recognizes the significant role of information that facilitates (or hinders) the operations of the system organization and its structural configurations. Both the system organization and its structural configurations depend on the information transmitted among organizational actors. Significantly, whatever the interactive processes that goes on among organizational actors, handling of information is the primary mechanism that shapes the structural configurations.

The groundwork for our analysis is based on traditional functionalist thinking, which postulates that (internal) organizations seek order and integration. However, taking actorinteraction in organizational construction processes into consideration, we go beyond functionalist theory to a conceptualization of structural variations at the cognitive level.

Although we apply constructs to this investigation of the structural formation of organizations at the micro level, our conceptualizations could be extended to macro-level 
analyses. The concepts of normative superstructure and cognitive superstructure (Johannessen, 1998) allow for extending the constructs elaborated in our study to the theorization of inter-organizational structures and structural coupling in organizational fields.

\section{REFERENCES}

Bausch, K. C. 2001. The Emerging Consensus in Social Systems Theory. New York: Kluwer Academic/Plenum Publishers.

Berger, P. and Luckmann, T. 1967. The Social Construction of Reality: A Treatise in the Sociology of Knowledge. London: Penguin Books.

DiMaggio, P.J. and Powell W.W. 1991. Introduction. In W. W. Powel and P. J. DiMaggio (eds.), The New Institutionalism in Organizational Analysis, Chicago: The University of Chicago Press.

Dissanayake, K. 2004 (a). The Concept of Organizational Construction. Unpublished Doctoral Dissertation, Meiji University, Japan.

Dissanayake, K. 2004 (b). The Construction of organizational environment, Studies in Business Administration, 21, 77-98.

Donaldson, L. 2001. The Contingency Theory of Organizations. California: Sage Publications.

Dow, G. K. 1988. Configurational and coactivational views of organizational structure, Academy of Management Review, 13 (1), 53-64.

Fayol, H. 1949. General and Industrial Management. London: Pitman.

Gerth, H.H. and Mills, C.W. (1948). From Max Weber: Essays in Sociology. London: Routledge \& Kegan Paul Ltd.

Giddens, A. 1979. Central Problems in Social Theory: Action, Structure and Contradiction in Social Analysis. London: Macmillan.

Hernes, T. and Bakken, T. 2003. Implications of self-reference: Niklas Luhmann's autopoiesis and organization theory, Organization Studies, 24(9), 1511-1535.

Johannessen, J-A. 1998. Organizations as social systems: The search for a systemic theory of organizational innovation processes, Kybernetes, 27 (4), 359-387.

Luhmann, N. 1990. Essays of Self-reference, New York: Columbia University Press.

Luhmann, N. 1995. Social Systems. California: Stanford University Press.

Mintzberg, H. 1979. The Structuring of Organizations: A Synthesis of the Research. New Jersey: Prentice-Hall Inc.

Pennings, J. M. 2002. Structural contingency theory: A reappraisal. In S. Clegg (ed.), Central Currents in Organization Theory: Fundamentals and Applications, 3, 
London: Sage Publications.

Silverman, D. 1970. The Theory of Organizations: A Sociological Framework. London: Heinemann Educational Books Ltd.

Stacy, R. D. 2001. Complex Responsive Processes in Organizations: Learning and Knowledge Creation. London: Routldge.

Takahashi, M. 2000. Soshiki no konfigereshonaru apurochi [The configurational approach to organizations] Social Science Review, Graduate School of Social Science, Meiji University, 39 (1), pp.227-238.

Tenbner, G. 1993. Law as an Autopoietic System. USA: Blackwell.

Weick, K.E. 1979. The Social Psychology of Organizing. California: Addison-Wesley Publishing Company.

Weick, K.E. 1995. Sensemaking in Organizations. Thousand Oaks: SAGE Publications.

Whitaker, R. 1995. Autopoietic Theory and Social Systems: Theory and Practice, Randall Whitaker's autopoiesis. Retrived 10, December 2004, from http://www.acm.org/sigs/sigois/auto/ATReview.html 
